\title{
Sensorless induction motor drive for electric vehicle application
}

\author{
J. Guzinski ${ }^{1} *$, H. Abu-Rub ${ }^{2}$ \\ ${ }^{1 *}$ Gdansk University of Technology, POLAND \\ ${ }^{2}$ Texas A\&M University at Qatar, QATAR \\ "Corresponding Author: e-mail: jarguz@pg.gda.pl, Tel +48-58-3472960,Fax.+48-58-3410880
}

\begin{abstract}
In this paper, an electric vehicle drive with a robust and low cost alternating current (AC) induction motor is presented. This approach is applied to an existing commercial utility electric vehicle where previously used direct current (DC) series motor was replaced by the new AC induction motor. The use of three-phase squirrel cage induction motor requires implementing of voltage source inverter supplied by DC voltage from vehicle battery system. A new DSP based voltage inverter is designed for the proposed drive. The used processor realizes the field oriented control algorithm with torque and flux closed loop control. The proposed drive does not require speed sensor, which make the solution sensorless and reliable on speed sensor faults. Motor speed is computed by the processor using speed observer. In this paper system description, control algorithms realization, and speed computation are presented. The paper includes the simulation and experimental results of the discussed system.
\end{abstract}

Keywords: Electric vehicle, induction motor, field oriented control, sensorless control.

\section{Introduction}

Currently there is a significant effort being done toward getting advanced electric vehicles (Szumanowski, 2000), (Ehsani et al, 2002). In such drives different motors are utilized. Because of the advancement in power electronics technology DC motors are replaced by more economical AC motors, such as squirrel cage induction machine (Bose, 2002), (Kirtley et al, 2007), (Guzinski, 2010).

Induction motor is currently one of the cheapest and most reliable electric machine. Due to absence of wearing parts this motor is maintenance-free machine. Induction motor characterizes high efficiency in wide operation range close to $90 \%$ in case of rotor aluminum cage or higher for motors with rotor copper cage (SIEMENS). The higher efficiency of the motors with cooper cage comes from decreasing of rotor, mechanical and stray losses. Additionally the operation temperature for copper cage motor is lower in comparison to motors with aluminum cage providing the reduction of the motors dimensions and the weight (Kirtley et al, 2007). The motor size reduction is specially important in the electric vehicles applications.

Realization of electric vehicle with squirrel cage motor requires special construction of the converter and using adequate control scheme. Power converter as well control method of induction motors are significantly more complicated compared to those of DC motor drives. According to fast development in power electronics and microprocessor technologies this complexity is no more an obstacle for the development of AC electric vehicle drives.

\section{Electric utility vehicle}

Electric commercial utility vehicles are the most common and widely used. They are standard vehicles often used for factory internal transport, high area gardening or in recreation use e.g. for golf players. A typical structure of such vehicle is presented in Figure 1. 


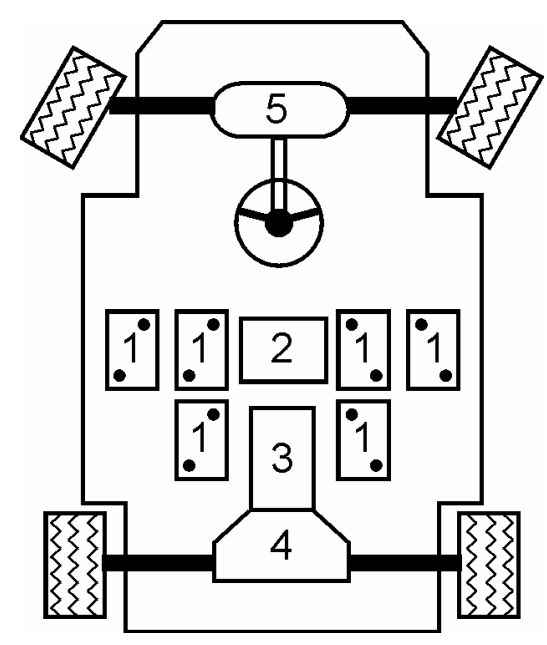

Figure 1. Typical structure of electric utility vehicle (1-batteries, 2-converter, 3-motor, 4-driving axle, 5-steering gear)

A typical transportation electric vehicle is a biaxial vehicle with rear drive axle. Electric motor is fed from the batteries through power electronics converter. The motor drives the vehicle wheels using a differential gear (Keoun, 1995).

Electric utility vehicles are mostly used for carrying two passengers and specific amount of luggage. An example view of that vehicle type is shown in Figure 2.

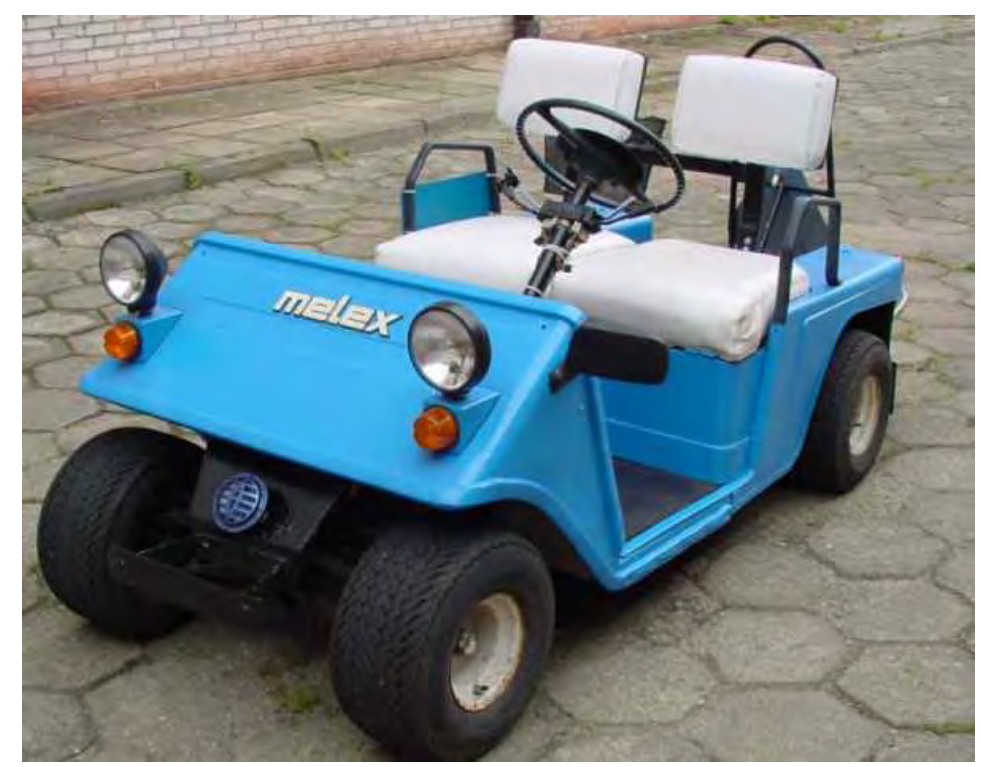

Figure 2. View of electric utility vehicle

The vehicle shown in Figure 2 was originally fed using $1.6 \mathrm{~kW}$ DC series motor. The vehicle battery system contains six leadacid batteries with a capacity of $180 \mathrm{Ah}$ and total voltage of $36 \mathrm{~V}$. This vehicle has been chosen for conversion purposes by using squirrel cage induction motor with microprocessor control.

\section{Electric AC motor drive}

For the modified electric vehicle the $3 \mathrm{~kW}$ two-pole squirrel cage motor was provided. Because of low voltage level of battery pack the motor was designed for a $24 \mathrm{~V}$ line-to-line voltage rating when connected in delta. Rated speed of the motor is $2835 \mathrm{rpm}$, which provides a maximum speed of the vehicle on flat road close to $37 \mathrm{~km} / \mathrm{h}$ for gear ratio in the driving axle $\mathrm{i} \approx 12$. Base speed, which is the border between first and second speed control area was set at the level of $25 \mathrm{~km} / \mathrm{h}$. The used motor $3 \mathrm{~kW}$ was selected to guarantee enough vehicle dynamics. E.g. for the vehicle going with speed equal to $25 \mathrm{~km} / \mathrm{h}$ the required motor mechanical output power is about $1.55 \mathrm{~kW}$ according to calculations and real operation measurement.

The motor nominal parameters are presented in Table 1. 
Table 1. Fonts, style and appearance

\begin{tabular}{|l|l|}
\hline \multicolumn{1}{|c|}{ Parameter } & \multicolumn{1}{c|}{ Value } \\
\hline Power $\mathrm{P}_{\mathrm{n}}$ & $3 \mathrm{~kW}$ \\
\hline Voltage $\mathrm{U}_{\mathrm{n}}$ & $24 \mathrm{~V}$ \\
\hline Current $\mathrm{I}_{\mathrm{n}}$ & $108.8 \mathrm{~A}$ \\
\hline Speed $\mathrm{n}_{\mathrm{n}}$ & $2835 \mathrm{rpm}$ \\
\hline Frequency $\mathrm{f}_{\mathrm{n}}$ & $50 \mathrm{~Hz}$ \\
\hline Stator resistance $\mathrm{R}_{\mathrm{s}}$ & $25.6 \mathrm{~m} \Omega$ \\
\hline Rotor resistance $\mathrm{R}_{\mathrm{r}}$ & $27.5 \mathrm{~m} \Omega$ \\
\hline Stator inductance $\mathrm{L}_{\mathrm{s}}$ & $2.64 \mathrm{mH}$ \\
\hline Rotor inductance $\mathrm{L}_{\mathrm{r}}$ & $2.64 \mathrm{mH}$ \\
\hline Mutual inductance $\mathrm{L}_{\mathrm{m}}$ & $2.58 \mathrm{mH}$ \\
\hline
\end{tabular}

To replace the previously used serial DC motor at first the DC series motor was dismounted and AC motor was coupled to vehicle differential gear. Finally, the AC motor was fixed to the gear and the parking brake was mounted on the non-driving shaft as is presented in Figure 3.

a)

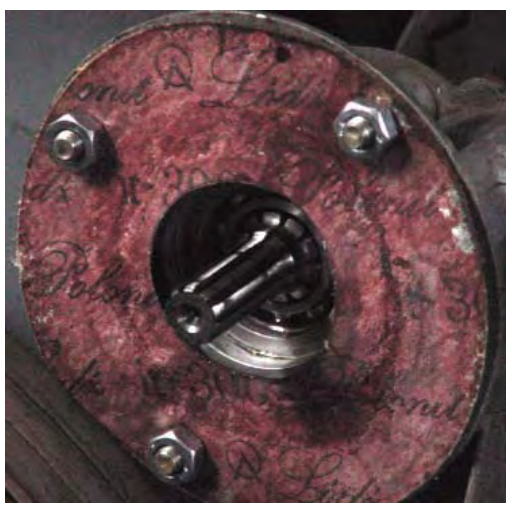

b)

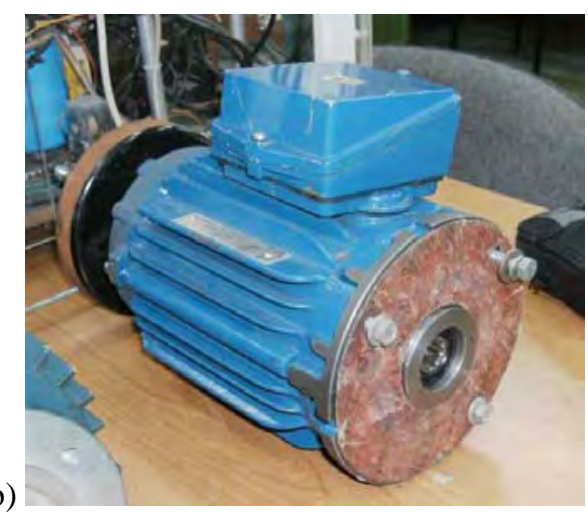

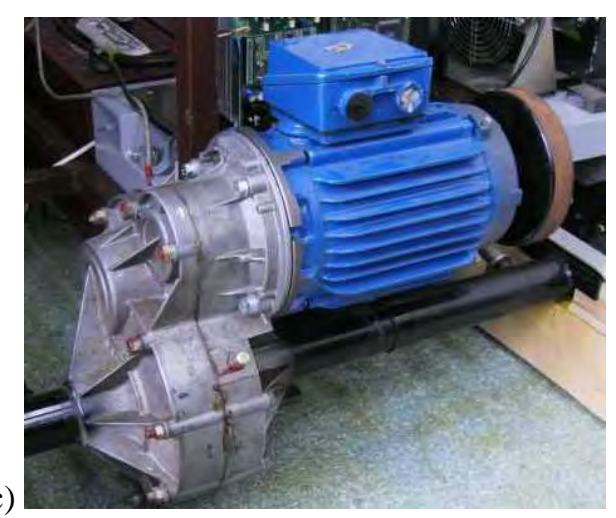

Figure 3. View: a) the input shaft of the differential gear b) motor with driving end shaft (right) and parking brake disc (left), c) AC motor fixed to the vehicle gear

\section{Electric vehicle power inverter}

The simplest solution of power electronics systems for electric vehicles is the DC motors. Such a system is the transistorized current chopper (Keoun, 1995). More complex power systems are necessary for drives with AC motors. In the vehicles ac drives usually structure with voltage inverter is used (Bose, 2002), (Bertoluzo and Buja, 2010), (Guzinski, 2010). The typical drive structure is presented in Figure 4.

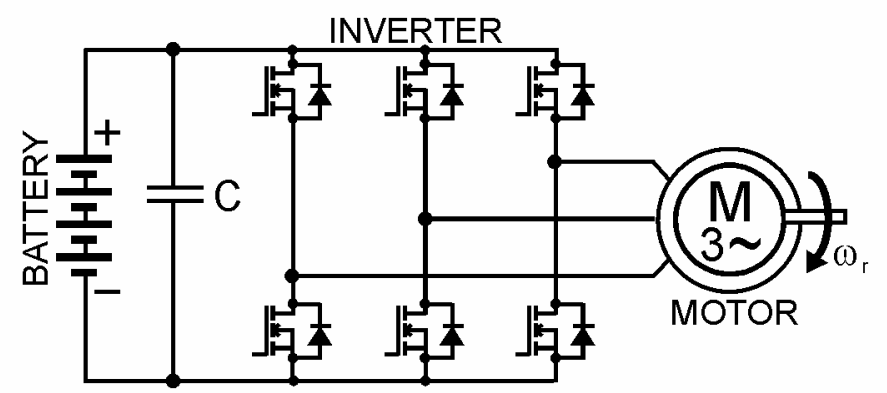

Figure 4. Electric vehicle voltage inverter 
In the utility vehicle solution, due to low battery pack voltage, it was necessary to use field-effect transistors as power switches of the inverter. Selected transistors are STE180NE10 with 180A and 100V nominal current and voltage respectively. These transistors provide low switching losses due to the high switch-on and switch-off times. The transistors have also low conducting losses because of low drain-source resistance $\mathrm{R}_{\mathrm{DS}(\text { on })}=4.5 \mathrm{~m} \Omega$. In the prepared inverter each semiconductor switch was made with two MOS transistors in parallel connected.

The drive requires the proper gate amplifiers specified for a use with insulated gate transistors. Each pair of transistors is controlled by the microprocessor through gate drivers M57962L. The gate amplifier M57962L type has embedded transistors overcurrent detection circuit. The detection is based on measurement of the transistor voltage drop in switch-on state. This type of protection is used for insulated gate bipolar transistors (IGBT). In M57962L driver the transistor overcurrent is detected if voltage drop is greater than approximately $6 \mathrm{~V}$. If the $6 \mathrm{~V}$ limit is exceed the driver embedded controller is blocking the transistor gate signal for a brief moment and gives fault signal to the microprocessor control system simultaneously. If the overcurrent fault signal is indicated by the driver microprocessor should react on fault by immediate switching off the commanded transistor gate signals.

In order to increase the drive robustness the inverter overcurrent protection type was implemented. Because of use metal-oxidesemiconductor (MOS) transistor instead of IGBT the overcurrent fault activation threshold was reduced by installing $R_{1}=18 \mathrm{k} \Omega$ resistor connecting in series with drain-source voltage measuring system. As a result the fault activation threshold was decreased to the level of $\mathrm{U}_{\mathrm{DS}} \approx 1.6 \mathrm{~V}$. The used driver scheme and characteristis of $\mathrm{U}_{\mathrm{DS}}\left(\mathrm{R}_{1}\right)$ are presented in Figure 5.
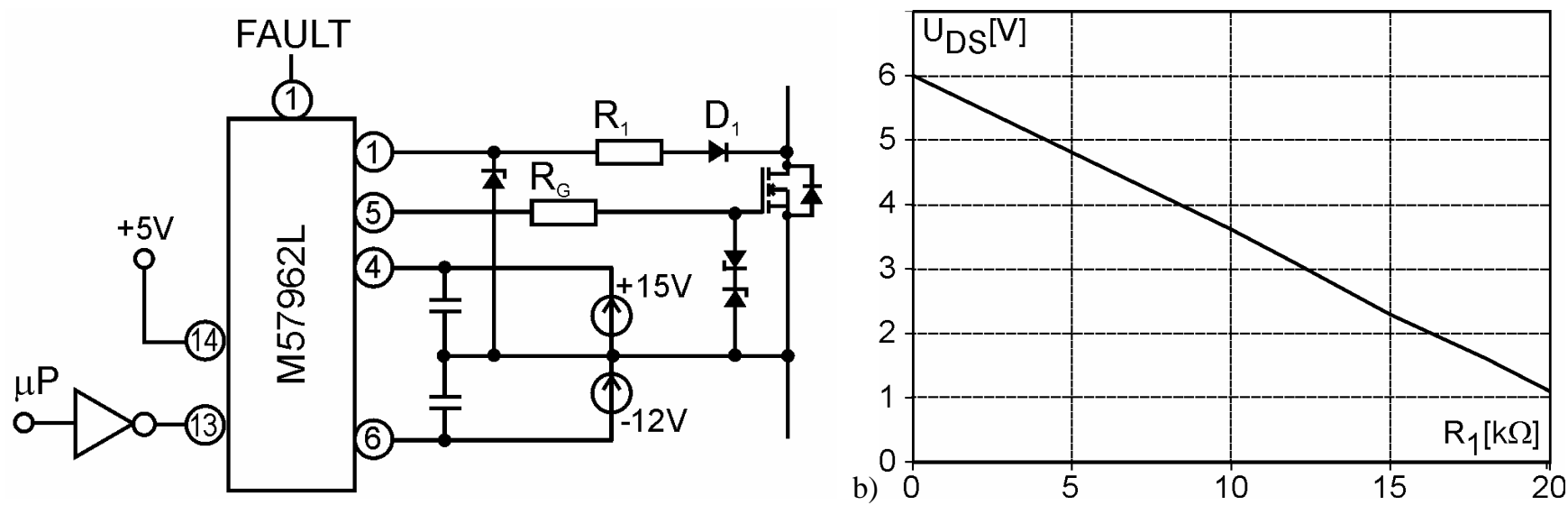

Figure 5. a) Gate driver scheme, b) Characteristic of $\mathrm{U}_{\mathrm{DS}}=\mathrm{f}\left(\mathrm{R}_{1}\right)$ for $\mathrm{M} 57962 \mathrm{~L}$ gate driver

Based on STE180NE10 transistor data sheet the transistor voltage drop at current $\mathrm{I}_{\mathrm{D}}=90 \mathrm{~A}$ is $\mathrm{U}_{\mathrm{DS}(\mathrm{on})}=1.1 \mathrm{~V}-$ if transistor junction is hot. Because of the absence of the MOS transistors characteristic $\mathrm{U}_{\mathrm{DS}(\mathrm{on})}\left(\mathrm{I}_{\mathrm{D}}\right)$ for the high currents it is difficult to found whether the voltage drop $\mathrm{U}_{\mathrm{DS}} \approx 1.6 \mathrm{~V}$ will be suitable for MOS transistors protection against overcurrent. However, to ensure safe operation of the whole system it was decided to use such additional inverter short circuit protection. The implemented overcurrent protection was verified experimentally in the real converter tests.

In electric vehicle drive the embedded driver overcurrent detection is an additional transistors protection function. The main inverter overcurrent protection is based on measurement of motor currents and comparison with maximal allowable current by the inverter microprocessor control system. If the maximal rating of the inverter output current is exceeded the all six transistor gate control signals are off immediately.

To measure the motor currents and the battery voltage the Hall-effect current and voltage sensors were used.

Each of the six gate drivers is supplied by auxiliary isolated 2 Watts DC/DC converters. Also other auxiliary supply comes for additional DC/DC converters. All of the auxiliary converters are supplied directly from the vehicle battery pack.

Depending on battery charge state and power consumption the battery voltage is variable over a wide range. Because of that the selected DC/DC converters were designed to operate with the supply voltage in a wide range - from 20V up to 50V approximately.

\section{Control scheme}

The control algorithm uses a microprocessor system SH65L type consisting of floating point digital signal processor (DSP) ADSP21065L and field gate array (FPGA) programmable logic system. The control system is equipped with RS232 interface that allows communication between the microprocessor and a personal computer. Communication has been used at the start of the system allowing the development of the necessary software designed in C language. Communication via RS232 also allows online data acquisition and commanding the desired motor torque or motor flux to the microprocessor control system.

In the software developed for SH65L system implements, a vector control method of induction motor and the estimation of the motor state variables. 
5.1 Vector control in the electric vehicle drive:

The structure of realized vector control scheme of the electric vehicle is shown in Figure 6.

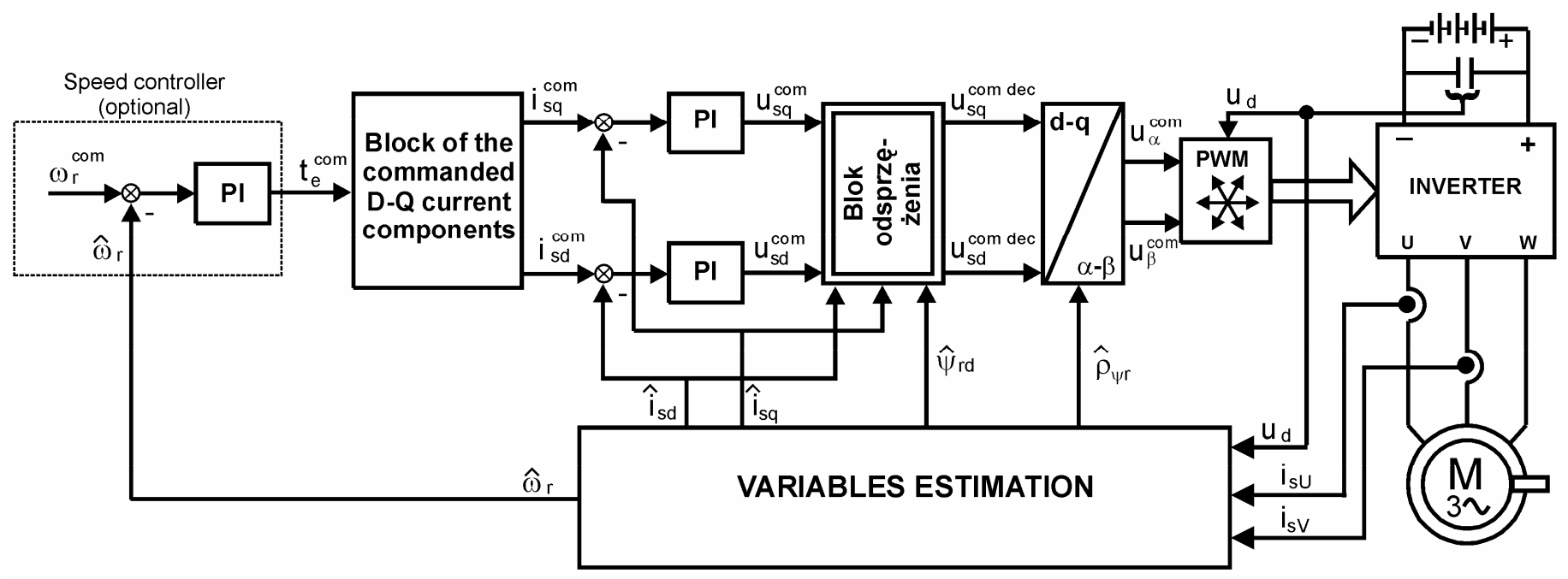

Figure 6. Field oriented control scheme of the electric vehicle

Field oriented control method, known popularly as vector control is widely used in modern industrial systems. The field oriented control method of the motor is realized for current components in dq rotating coordinate system presented in Figure 7 (Vas, 1990), (Bose, 2002), (Guzinski, 2010).

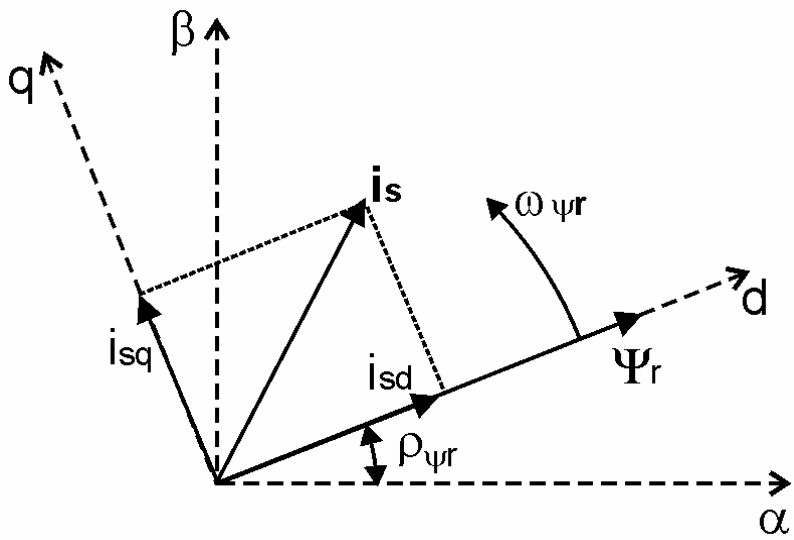

Figure 7. Field oriented control in coordinate system dq connected with rotor flux position $\psi_{\mathrm{r}}$

In the field oriented control system a stator current d-component adjusts the rotor flux in the motor, while the combination of $d$ and q- components adjusts the motor torque. By applying the decoupling block in the particular $\mathrm{d}$ and q control parts the control of flux and torque can be done independently - as in the case of separately excited DC machine.

With use of field oriented control (FOC) the squirrel cage induction motor drive has better performance than separately excited DC machine. This follows from the fact that in the DC machine brushes position should be set in position depending on the rotation direction and the motor load level - which requires proper mechanical operation. This mechanical operation is not required in the case of squirrel cage induction motor with FOC.

A typical vehicle drive system works without speed controller. This role satisfies the driver (Guzinski et al, 2010). Motor torque $\mathrm{t}_{\mathrm{e}}{ }^{\text {com }}$ setpoint is the vehicle accelerator pedal. However, in the discussed drive system it is used a digital speed controller implemented as an optional function of the control algorithm. This allows easily testing of the vehicle drives - without the need for long-term load matched to the generated torque by the motor.

In a typical FOC the motor flux is kept constant if the motor speed is nominal or lower. The flux is decreased only for motor high speed operation. 
In this electric vehicle a different flux control principle is used. For the presented solution the rotor flux is reduced in the whole speed range. This leads to two cases:

A. increasing the efficiency of the whole drive by reducing energy consumption for motor working with light load level,

B. protection of the vehicle mechanical transmission against damage in case of failure in the inverter transistors.

\section{Case A}

It is unnecessarily maintaining rated flux if the motor is only partially loaded. For that state the flux can be reduced to a value appropriate to the motor load level. In case when the motor load is increased the motor torque is increased as well because the commanded flux growths.

\section{Case B}

If motor flux is smaller than nominal one the vehicle mechanical transmission is protected against sudden torque high increase. The rapid torque enlargement could be caused by one of the inverter transistors shortening. That failure has significant influence on the vehicle passengers safety. The destruction of the gearbox may lead to locking of the vehicle wheels and unexpected rapid vehicle braking.

If one of the inverter switch shortening happens in case of smaller than nominal flux value, the motor torque impulse is also smaller - it is explained graphically in Figure 8.
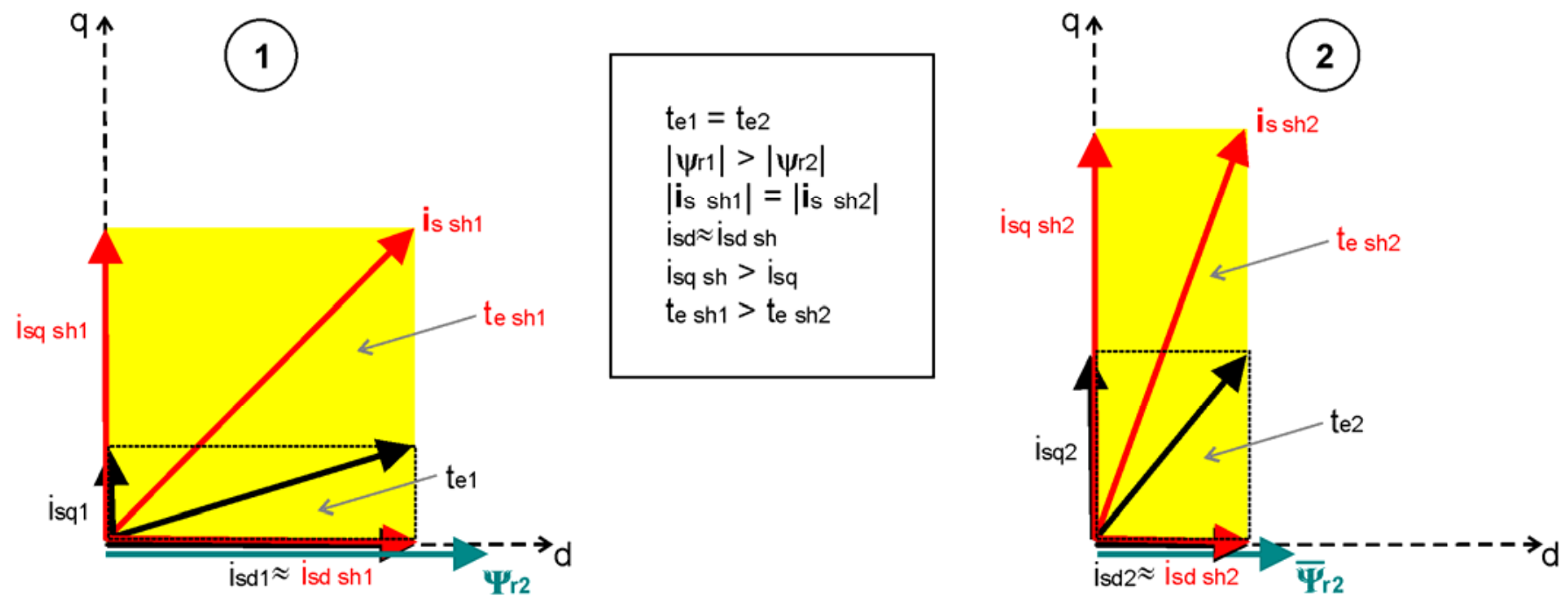

Figure. 8. Vehicle drive mechanical transmission system protection by decrease of the motor flux

Figure 8 shows two cases of system operation during shortening of one transistor in the inverter: 1) at rated flux, 2) at reduced flux. In both cases before the inverter failure the motor torque were the same, ie $t_{\mathrm{e} 1}=\mathrm{t}_{\mathrm{e} 2}$. Because of the larger time constant of current control loop for $d$ axis the value of $i_{s d}$ practically is not changed at initial stage of shortening. So during inverter switch shortening the stator current modules are the same in both cases, i.e. $\left|\mathbf{i}_{\mathrm{s} \mathrm{sh} 1}\right|=\left|\mathbf{i}_{\mathrm{s} \mathrm{sh} 2}\right|$. Hence if the d-current component does not change i.e. $i_{s d} \approx i_{s d ~ s h}$, then the $q$ component must change adequately i.e. $i_{s q ~ s h}>i_{s q}$.

Motor torque is proportional to the surface area of a rectangle formed by the d- and q-components of the stator current:

$$
t_{e s h}=k \cdot i_{s d} \cdot i_{s q}
$$

where: $\mathrm{k}$ - motor construction coefficient.

Therefore, in the case of short circuit occurrence in the inverter system, with a reduced flux of the motor a torque spike should be smaller:

$$
t_{e s h 2}<t_{e s h 1}
$$

The simulation results showing the motor torque peak when one of the inverter's transistors is shortening are presented in Figure 9 for two cases: a) for weakened flux, and b) with nominal flux. 
a)

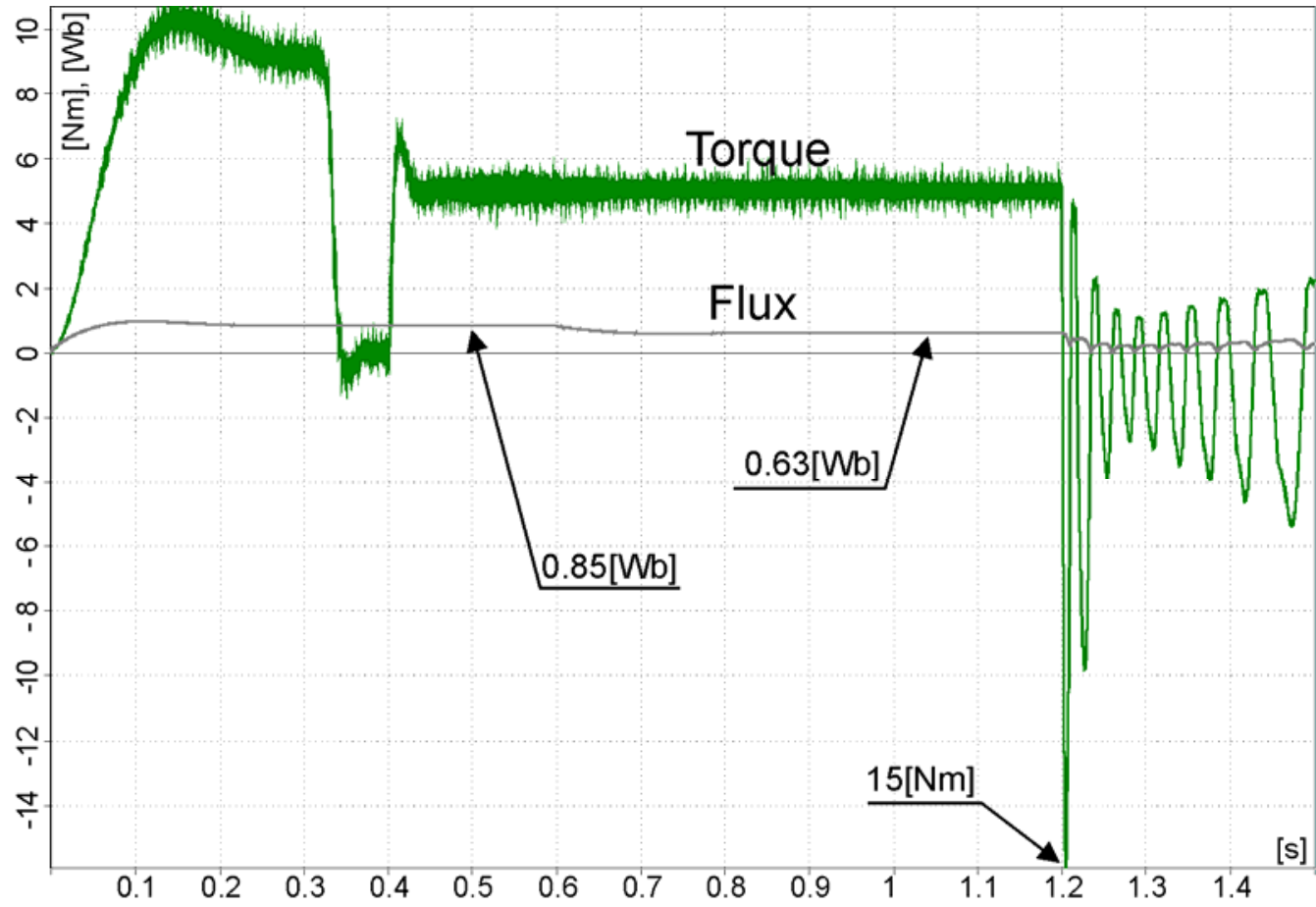

b)

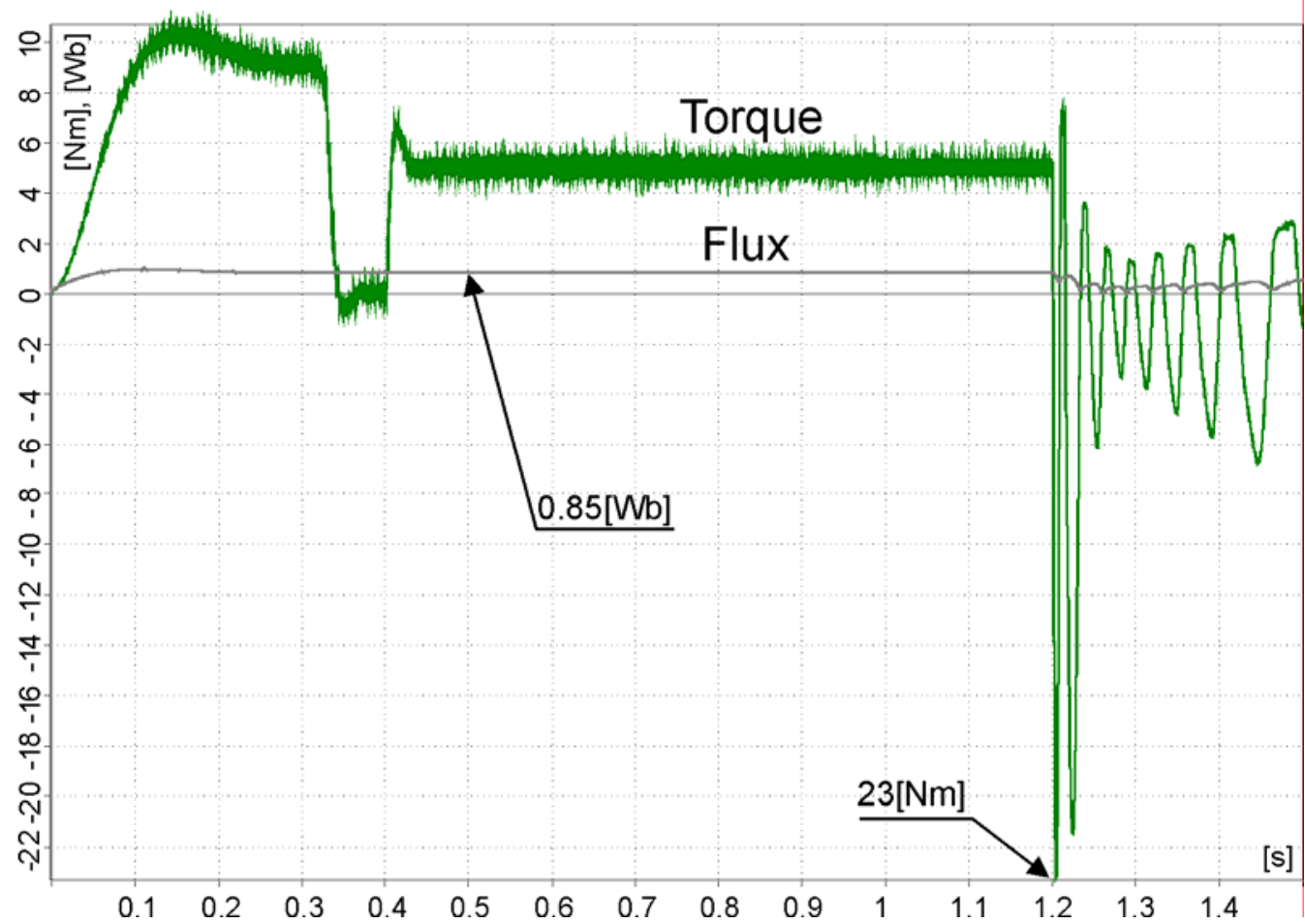

Figure 9. Simulation results for transistor shorting in the inverter at 1.2s for two cases:

a) with weakened flux, b) with nominal flux

For test presented in Figure 9 is noticeable that reducing the $75 \%$ flux decreasing results in $65 \%$ motor torque peak decreasing in case of the inverter fault.

In most of typical FOC industrial applications the torque control by stator d-component variation is not used. It results form that the dynamics of the motor torque control system by changing the flux is lower than the typical dynamics of vector control system in which the motor torque is regulated only by the current q-component. Fortunately the low dynamics is not critical parameter for 
the utility electric vehicles drive because of the high mechanical time constant of the entire vehicle. The vehicle mechanical constant is much greater than mechanical time constant of the electric motor.

\subsection{State variables computation in the electric vehicle drive:}

For the FOC vehicle system it is necessary to know: the value of motor currents, position and the module of the rotor flux and the actual motor speed.

In the vehicle FOC application the current trends in industrial systems is that the flux and speed is calculated on-line with the observer system use, therefore it is decided to drop the motor speed sensor from the drive and to calculate the motor speed in real time (Krzeminski, 2000), (Krzeminski, 2008), (Casadei et al, 2010), (Fujimoto and Yamauchi, 2010). This caused reducing costs and increasing robustness of the vehicle. The speed sensor removal simplifies both the mechanical design of the vehicle and its electrical system by eliminating of specific cables.

In the proposed electric vehicle drive the speed observer with extended motor model is implemented (Krzeminski, 2000), (Krzeminski, 2008). The observer base block structure is presented in Figure 10.

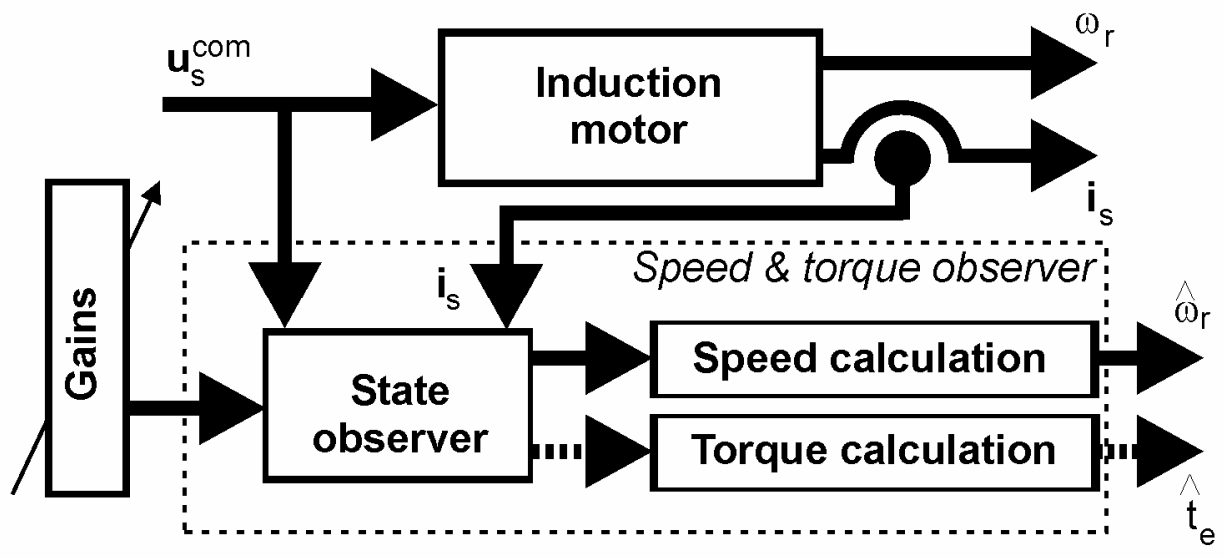

Figure 10. State observer for induction motor electric vehicle drive

The observer, based on knowledge of currents and voltages of the motor and machine parameters, calculates selected state variables of the motor in real time by microprocessor control system. Motor voltage is not measured but only computed in the control system, based on measured battery voltage, and information about the switching states of the inverter. In the used state observer the following variables are calculated: motor speed, rotor flux magnitude angle flux vector position as well motor electromagnetic torque.

The observer equations are as follows (Krzeminski, 2008):

$$
\begin{gathered}
\frac{d \hat{i}_{s \alpha}}{d \tau}=-\frac{R_{s} L_{r}^{2}+R_{r} L_{m}^{2}}{L_{r} w_{\sigma}} \hat{i}_{s \alpha}+\frac{R_{r} L_{m}}{L_{r} w_{\sigma}} \hat{\psi}_{r \alpha}+\frac{L_{m}}{w_{\sigma}} \hat{\xi}_{\beta}+\frac{L_{r}}{w_{\sigma}} u_{s \alpha}^{c o m}+k_{3}\left(i_{s \alpha}-\hat{i}_{s \alpha}\right) \\
\frac{d \hat{i}_{s \beta}}{d \tau}=-\frac{R_{s} L_{r}^{2}+R_{r} L_{m}^{2}}{L_{r} w_{\sigma}} \hat{i}_{s \beta}+\frac{R_{r} L_{m}}{L_{r} w_{\sigma}} \hat{\psi}_{r \beta}-\frac{L_{m}}{w_{\sigma}} \hat{\xi}_{\alpha}+\frac{L_{r}}{w_{\sigma}} u_{s \beta}^{c o m}+k_{3}\left(i_{s \beta}-\hat{i}_{s \beta}\right) \\
\frac{d \hat{\psi}_{r \alpha}}{d \tau}=-\frac{R_{r}}{L_{r}} \hat{\psi}_{r \alpha}-\xi_{\beta}+R_{r} \frac{L_{m}}{L_{r}} \hat{i}_{s \alpha}-k_{2} S_{b} \hat{\psi}_{r \alpha}+S\left(k_{2} k_{3} \hat{\psi}_{r \beta}\left(S_{b}-S_{b F}\right)+k_{5}\left(\left(S_{x}-S_{x F}\right) \hat{\psi}_{r \alpha}-\left(S_{b}-S_{b F}\right) \hat{\psi}_{r \beta}\right)\right) \\
\frac{d \hat{\psi}_{r \beta}}{d \tau}=-\frac{R_{r}}{L_{r}} \hat{\psi}_{r \beta}+\xi_{\alpha}+R_{r} \frac{L_{m}}{L_{r}} \hat{i}_{s \beta}-k_{2} S_{b} \hat{\psi}_{r \beta}+S\left(-k_{2} k_{3} \hat{\psi}_{r \alpha}\left(S_{b}-S_{b F}\right)+k_{5}\left(-\left(S_{x}-S_{x F}\right) \hat{\psi}_{r \beta}-\left(S_{b}-S_{b F}\right) \hat{\psi}_{r \alpha}\right)\right) \\
\frac{d \hat{\xi}_{\alpha}}{d \tau}=-\hat{\omega}_{\psi r} \hat{\xi}_{\beta}-k_{1}\left(i_{s \beta}-\hat{i}_{s \beta}\right)
\end{gathered}
$$




$$
\begin{aligned}
& \frac{d \hat{\xi}_{\beta}}{d \tau}=\hat{\omega}_{\psi r} \hat{\xi}_{\alpha}+k_{1}\left(i_{s \alpha}-\hat{i}_{s \alpha}\right) \\
& \frac{d S_{b F}}{d \tau}=\frac{1}{T_{S b}}\left(S_{b}-S_{b F}\right) \\
& \frac{d \hat{\omega}_{r F}}{d t}=\frac{1}{T_{K T}}\left(\hat{\omega}_{r}-\hat{\omega}_{r F}\right) \\
& \frac{d S_{x F}}{d \tau}=\frac{1}{T_{S x}}\left(S_{x}-S_{x F}\right) \\
& S=\left\{\begin{array}{rll}
1 & \text { if } & \hat{\omega}_{\psi r}>0 \\
-1 & \text { if } & \hat{\omega}_{\psi r} \leq 0
\end{array}\right. \\
& S_{x}=\hat{\xi}_{\alpha} \hat{\psi}_{r \alpha}+\hat{\xi}_{\beta} \hat{\psi}_{r \beta} \\
& S_{b}=\hat{\xi}_{\alpha} \hat{\psi}_{r \beta}-\hat{\xi}_{\beta} \hat{\psi}_{r \alpha} \\
& \hat{\omega}_{\psi r}=\hat{\omega}_{r F}+R_{r} \frac{L_{m}}{L_{r}}\left(\frac{\hat{\psi}_{r \alpha} \hat{i}_{s \beta}+\hat{\psi}_{r \beta} \hat{i}_{s \alpha}}{\hat{\psi}_{r \alpha}^{2}+\hat{\psi}_{r \beta}^{2}}\right) \\
& \hat{\omega}_{r}=\frac{\hat{\zeta}_{\alpha} \hat{\psi}_{r \alpha}+\hat{\zeta}_{\alpha} \hat{\psi}_{r \alpha}}{\hat{\psi}_{r \alpha}^{2}+\hat{\psi}_{r \beta}^{2}}
\end{aligned}
$$

where:

$$
w_{\sigma}=L_{r} L_{s}-L_{m}^{2}
$$

and:

$\mathrm{i}_{\mathrm{s} \alpha}, \mathrm{i}_{\mathrm{s} \beta}, \psi_{\mathrm{r} \alpha}, \psi_{\mathrm{r} \beta} \omega_{\mathrm{r}}$ - stator current and rotor flux components and motor mechanical speed respectively, $\mathrm{u}_{\mathrm{s} \alpha}{ }^{\text {com }}, \mathrm{u}_{\mathrm{s} \beta}{ }^{\text {com }}-\mathrm{stator}$ commanded voltage components, $R_{r}, R_{s}, L_{r}, L_{s}, L_{m}$ - motor equivalent circuit parameters, , $\wedge$ - denotes variable calculated in the observer, $\xi_{\alpha}, \xi_{\beta}$ - components of the motor electromotive forces, $\omega_{\psi \mathrm{r}}, \omega_{\psi \mathrm{rF}}-$ angular speed of the motor flux vector and its filtered value, $\mathrm{k}_{1}, \mathrm{k}_{2}, \mathrm{k}_{3}, \mathrm{k}_{4}, \mathrm{k}_{5}$ - observer gains, $\mathrm{S}_{\mathrm{x}}, \mathrm{S}_{\mathrm{xF}}$ - additional variables used to stabilize the observer work, $\mathrm{T}_{\mathrm{Sx}}$ - time constant of the $\mathrm{S}_{\mathrm{x}}$ filter.

The given speed observer system is based on the Luenberger observer theory with using of motor electromotive forces as additional state variables. The mechanical equation of the system was omitted and the motor mechanical speed is treated as variable parameter of the motor.

Due to work of the observer with corrective action the system is insensitive to changes in machine parameters. The observer gains and time constant were tuned empirically in the simulation software.

\section{Experiments}

Initially, the entire drive system of the electric vehicle assembled in the laboratory, was prepared as the stationary test bench. The principal parts of the experimental setup are shown in Figure 11. 
1)

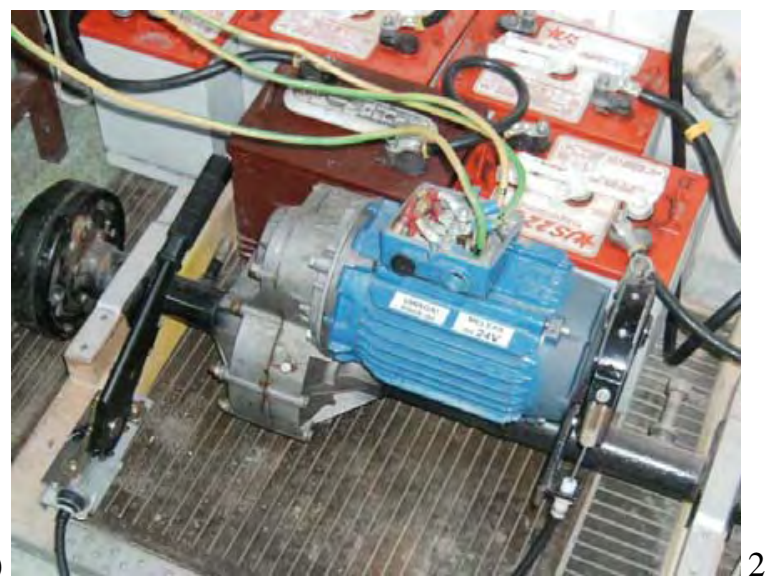

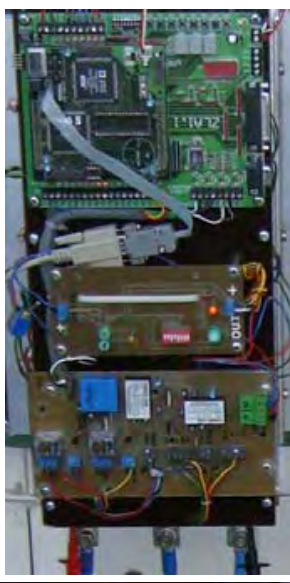

2)

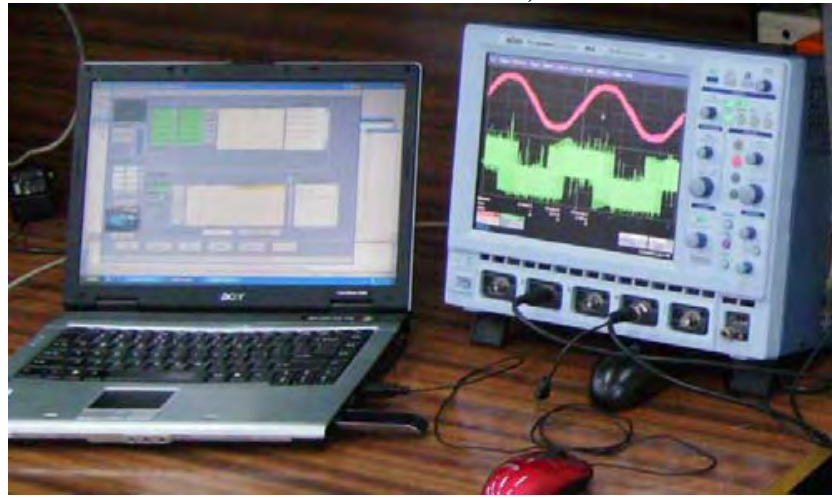

3)

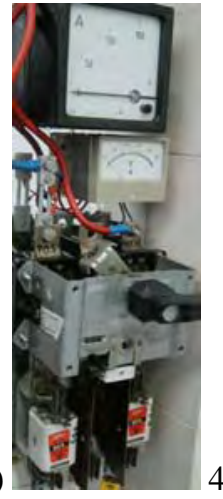

Figure 11. Experimental setup for testing electric vehicle drive (1-motor with differential gear, brake and batteries, 2-inverter, 3-main switch, fuses and meters, 4- computer with control panel and data acquisition software and digital oscilloscope)

In the first stage the operation of pulse width modulation (PWM) with commanded values of motor stator voltage and frequency was tested. Example of the obtained current waveform is shown in Figure 12.

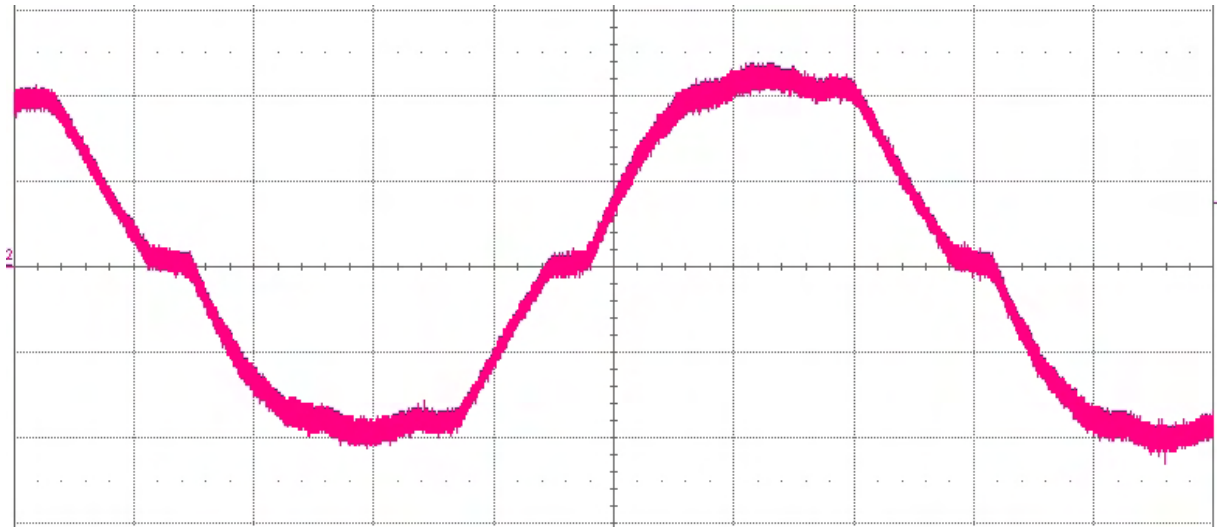

Figure 12. Motor phase current without dead-time compensation (50A/div, 100ms/div)

Motor current presented in Figure 12 is distorted from the sine wave shape. This is due to the lack of dead time compensation in PWM algorithm. Providing dead times is necessary for proper operation of the inverter, and has a significant impact on the accuracy of the generated voltage and on currents distortion. In the prepared system the dead time was set to $2 \mu$ s. To assure better system performance the dead time was compensated by proper changes in PWM control. The compensation was based on analysis of the inverter output current direction flow according to the relation:

$$
t_{u, v, w}^{\bmod }=t_{u, v, w}^{c a l}+t_{d} \cdot \operatorname{sgn}\left(i_{u, v, w}\right)
$$


where: $t_{u, v, w}^{c a l} \quad$ - is transistors switchover calculated time for the successive inverter leg, $t_{u, v, w}^{\text {mod }}$ is corrected value of $t_{u, v, w}^{c a l}$ according to the current direction and $i_{u, v, w}$ is inverter output current.

With (18) correction rule added to PWM algorithm the motor current shape has been improved as is presented in Figure 13.

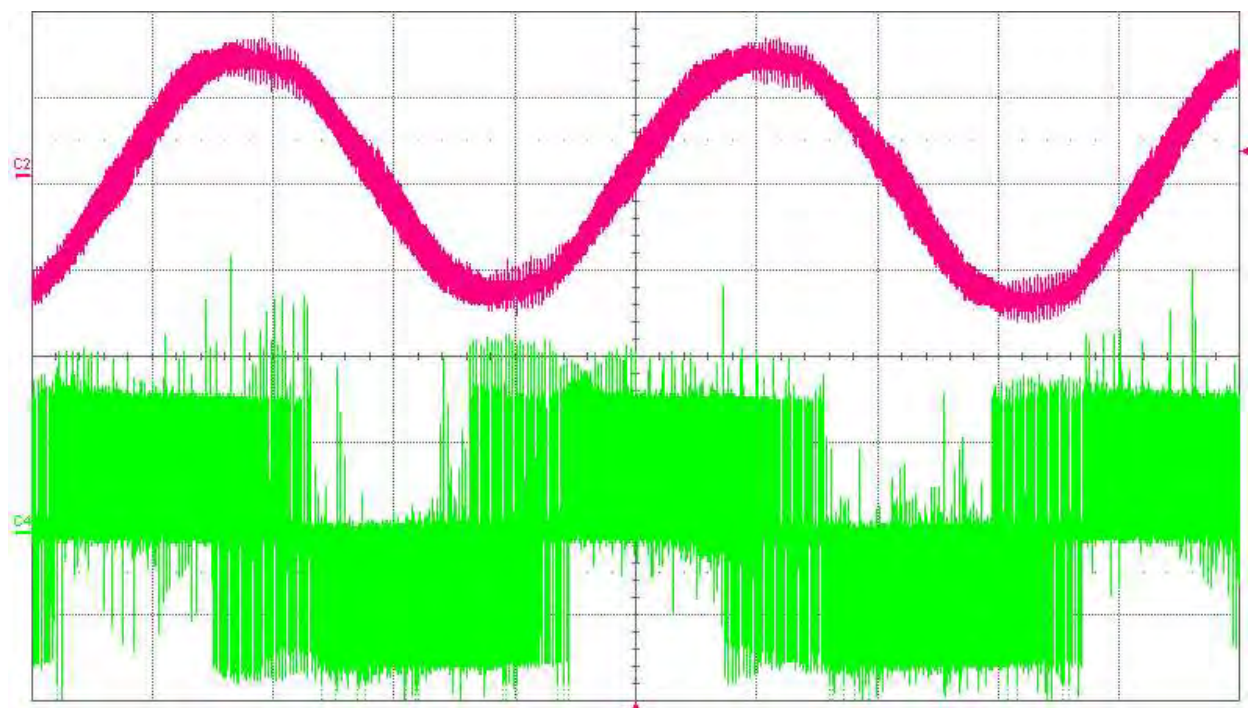

Figure 13. Inverter output current (upper waveform) and voltage (lower waveform) in case of the dead time compensation (10 ms/div, 50A/div, 20V/div)

The switching frequency of the prepared PWM inverter was $3.3 \mathrm{kHz}$. The adequate AC component is noticeable in Figure 13 current waveform. The current total harmonic distortion (THD) coefficient is less than $4.5 \%$.

Examples of overall drive operation with vector control and with variables estimation are presented in Figures $14-17$.

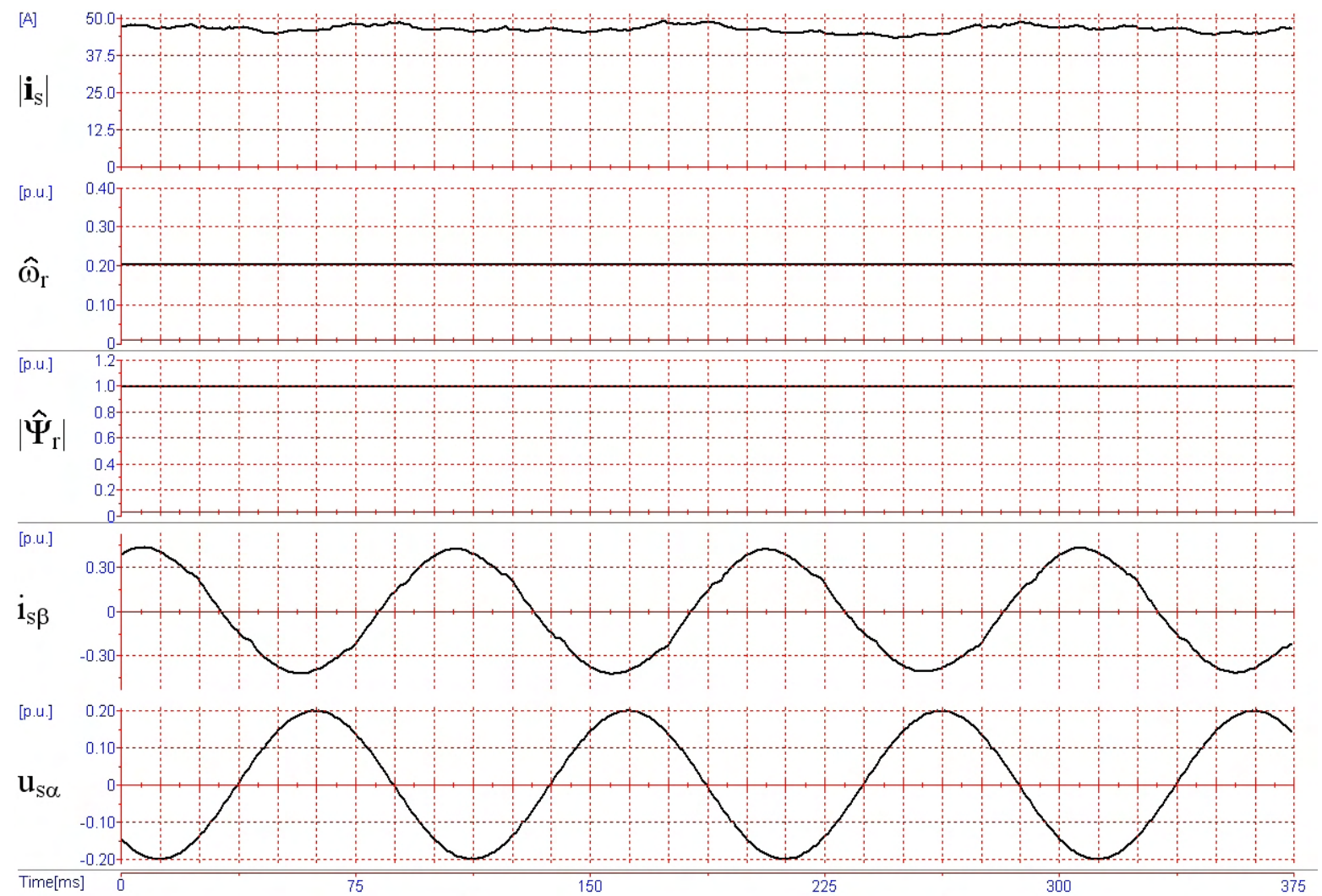

Figure 14. Experimental results of the electric vehicle drive - constant motor speed $600 \mathrm{rpm}$ 


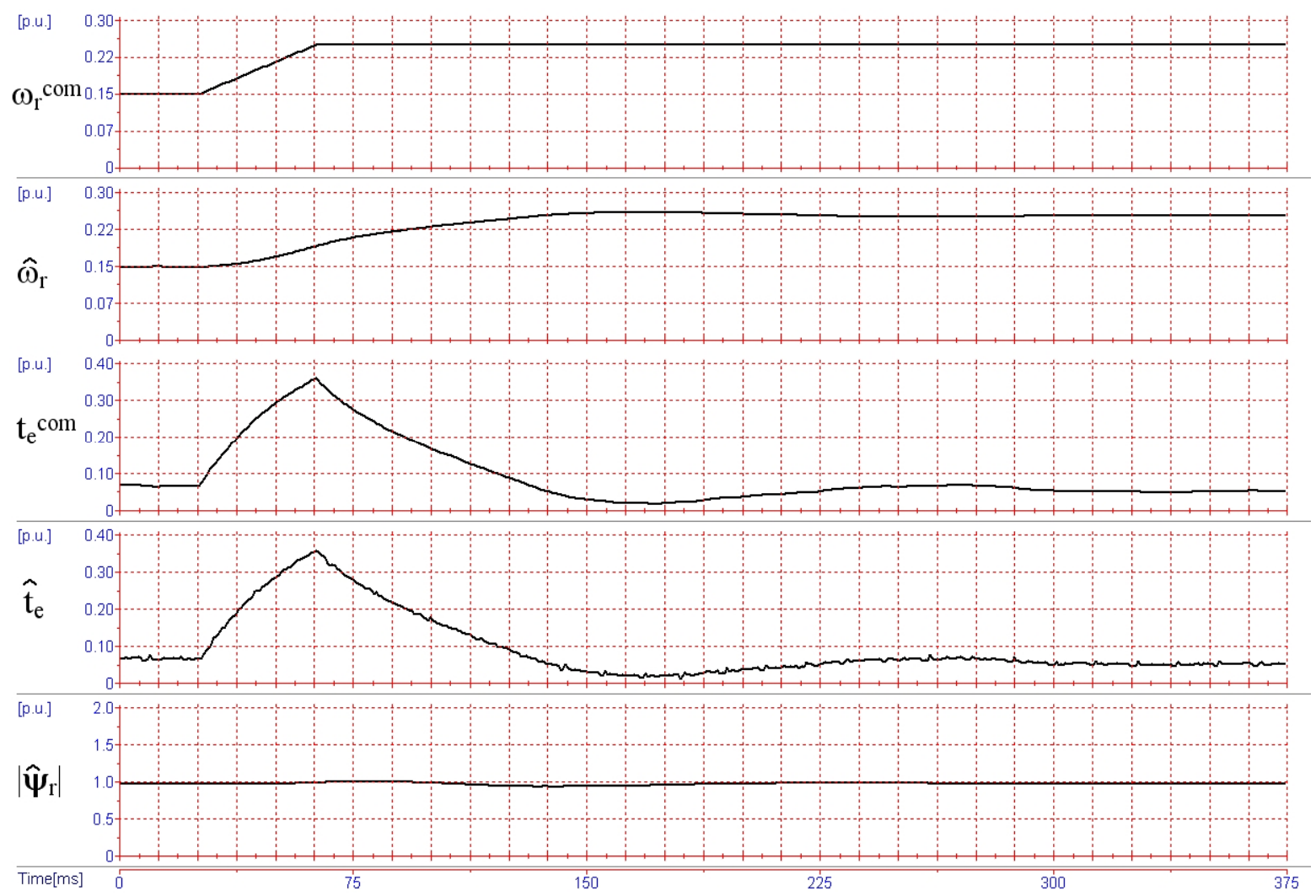

Figure 15. Experimental results of the electric vehicle drive - motor speed increasing

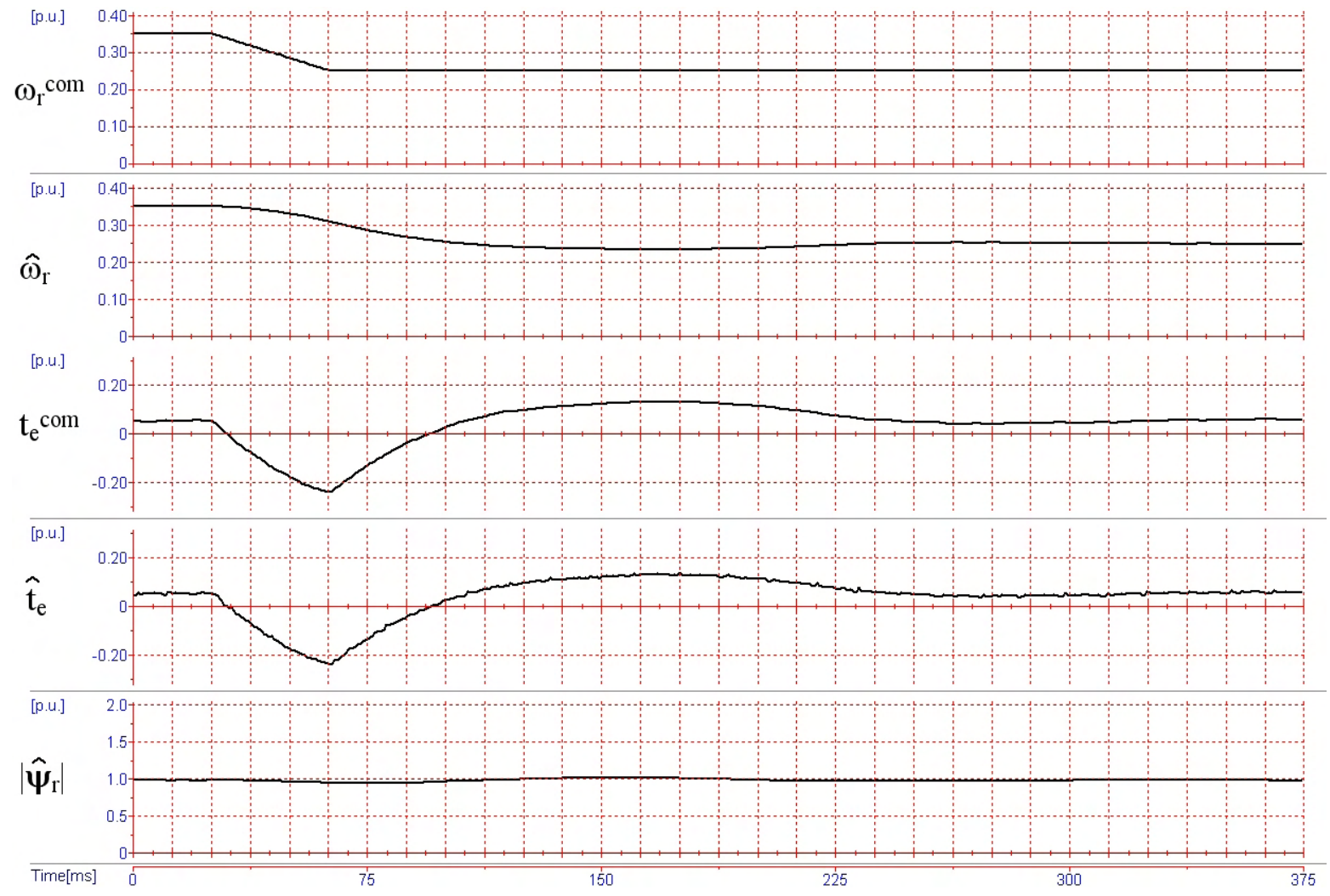

Figure 16. Experimental results of the electric vehicle drive - motor speed decreasing 


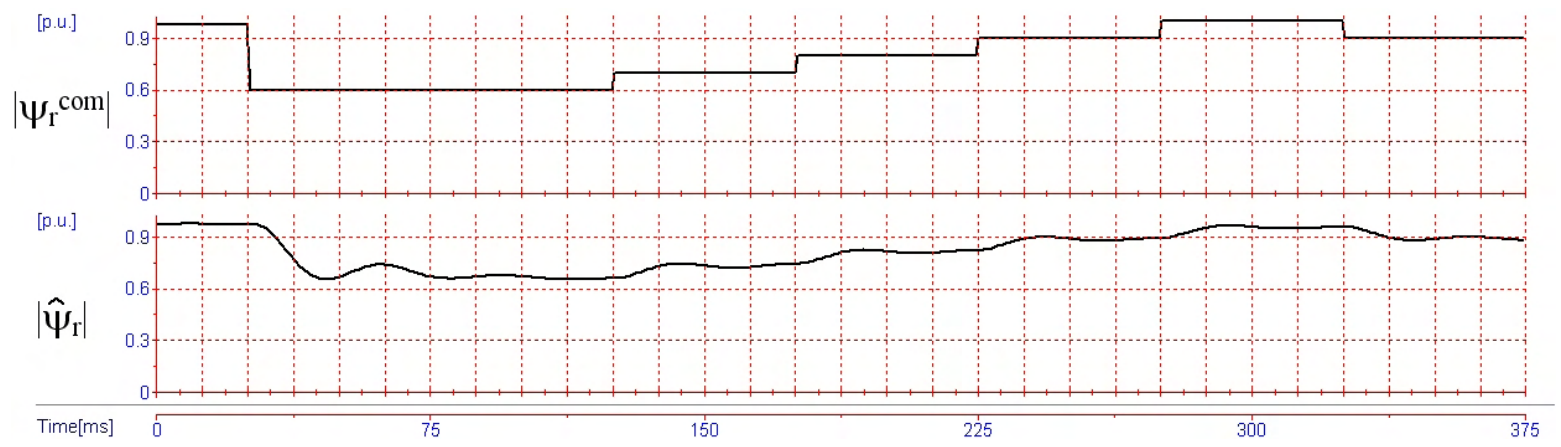

Figure 17. Experimental results of the electric vehicle drive - motor flux changes during constant motor speed $600 \mathrm{rpm}$

In all presented experimental results the per unit system (p.u.) is used i.e. variables are related to their nominal values (Krzeminski, 2000), (Guzinski et al, 2010). Only in Figure 14 a magnitude of the motor current is shown in real unit i.e. in amps.

In Figure 14 are presented waveforms in steady state with command speed 0.2 p.u., related to the vehicle speed approximately 5 $\mathrm{km} / \mathrm{h}$.

Figure 15 and Figure 16 show the transient waveforms of drive operation during increasing and decreasing of motor speed. The transient speed, motor torque and flux are regulated according to the command values. The dynamics of system operation has been limited in order to avoid rapid changes in motor torque, which could have significant effect on the later comfort of the vehicle use.

Figure 17 illustrates the operation of flux control system for the motor operation for no load and constant speed $600 \mathrm{rpm}$. As it was noticeable in previous tests, the proposed drive works properly. Controlled value of the rotor flux signal is set according to the command value.

Figure 18 shows error signal of motor speed estimation by observer use.

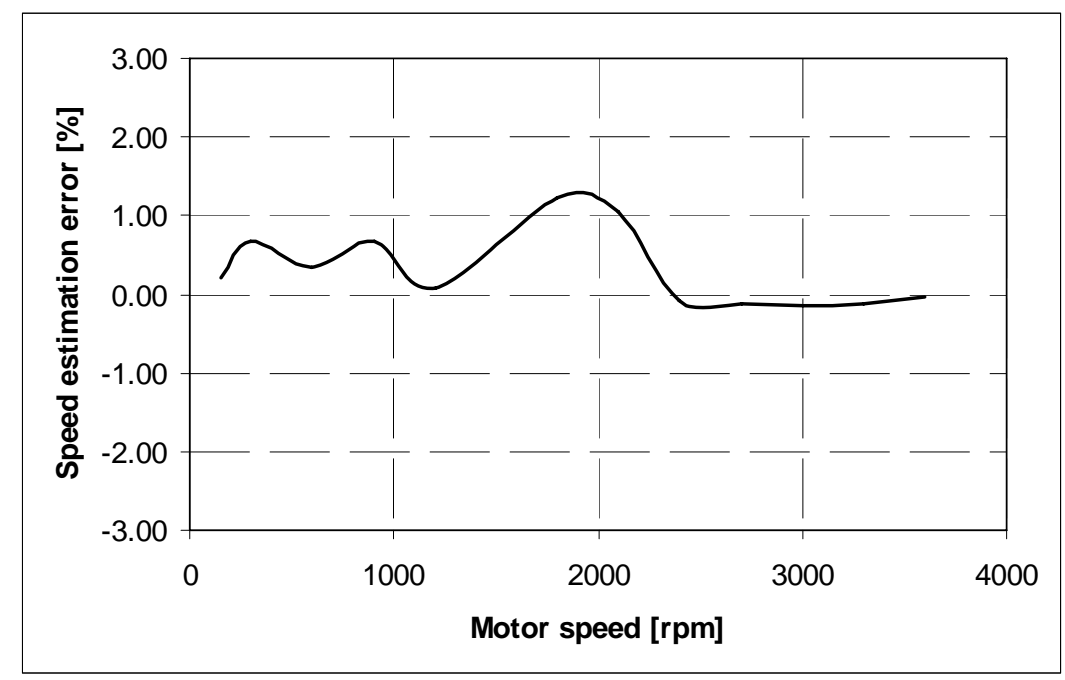

Figure 18. Waveform of speed estimation error

The experimental setup for the prepared electric vehicle drive was not equipped with a speed sensor. So for investigation purposes the motor speed was measured by hand-operated electronic tachometer. So the speed estimation error was determined only in stay state drive operation. As is noticeable in Figure 18 the speed calculation error does not exceed $2 \%$ for the expected operation range of the electric vehicle.

The relationship between battery pack current consumption and the rotor flux magnitude is in Figure 19. 


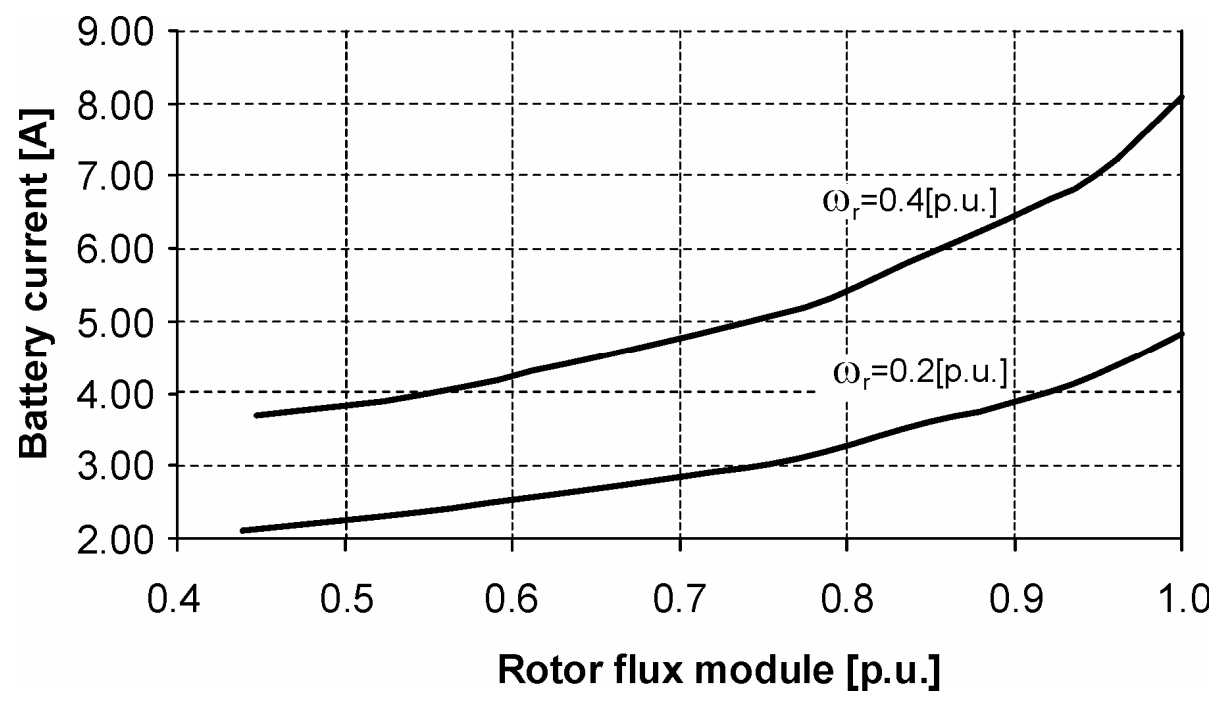

Figure 19. Relation between rotor flux module and the battery current consumption in case of motor flux weakening

Characteristics presented in Figure 19 were obtained for the motor running at constant speed - $1200 \mathrm{rpm}$ and $600 \mathrm{rpm}$ i.e. 0.4 p.u. and 0.2 p.u.. In both cases motor was working without load. It is evident that flux $50 \%$ reducing results in the same reduction of the battery current consumption.

\section{Conclusions}

The proposed drive could be a practical solution for use in modern electric vehicles. Use of squirrel-cage induction motor raises the drive robustness and decreases the cost of the drive compared to other solutions with different electric motors type. In addition, the reliability was additionally increased because of operating in sensorless mode where speed sensor is replaced by computational algorithm. The drive has been run on the experimental stationary test bench using a real torque transmission system of the utility electrical vehicle. The obtained tests have confirmed the proper operation of the drive according to the concepts presented in the paper.

\section{References}

Bertoluzzo M., Buja G. 2010. Propulsion systems for light electric vehicles. IEEE International Symposium on Industrial Electronics, ISIE 2010, 4-7 July, Bari, Italy.

Bose B. 2002. Modern power electronics and AC drives. Prentice Hall PTR.

Casadei D., Mengoni M., Serra G., Rossi C., Tani A., Zarri L.: Robust control schemes for induction motor drives for electric vehicle applications. International Conference and Exhibition on Ecological Vehicles and Renewable Energies, EVER 2010, March 25-28, 2010, Monaco.

Ehsani M., Gao J., Sebastien E., Gay E., Emadi A. 2005. Modern electric, and hybrid electric, and Fuel Cell Vehicles. Fundamentals, theory, and design. CRC Press, London, New York, Washington.

Fujimoto H., Yamauchi Y. 2010. Advanced motion control of electric vehicle based on lateral force observer with active steering. IEEE International Symposium on Industrial Electronics ISIE 2010, 4-7 July, Bari, Italy.

Guzinski J., Krzeminski Z., Abu-Rub H., Lewicki A. 2010. Torque transmission diagnostic system for high-speed train using statespace observer, International Journal of Electromotion, Vol. 17, No 1, January - March.

Guzinski J. 2010. Electric vehicle drives with induction motor. Magazine Drives and Control. No 2 - February. (in Polish): www.nis.com.pl

Keoun B.C. 1995. Designing an electric vehicle conversion. Southcon/95, 7-9 March, Fort Lauderdale, FL, USA.

Kirtley J.L.; Cowie J.G.; Brush E.F.; Peters D.T.; Kimmich, R.; Improving induction motor efficiency with die-cast copper rotor cages, IEEE Power Engineering Society General Meeting. 24-28 June 2007, Tampa, FL, USA.

Krzeminski Z. 2008. Observer of induction motor speed based on exact disturbance model. International Conference EPE-PEMC 2008, Poznan, Poland.

Krzeminski Z. 2000. Sensorless control of the induction motor based on new observer. International Conference on Power Electronics, Intelligent Motions and Power Quality PCIM, Nuremberg, Germany.

SIEMENS: New generation of Alu 1LE1 motors - Technology. 2010. WWW page: http://siemens.industrialpartner.com/drivesmotors/ac-motors/low-voltage-motors/iec-motors/1le1-motor-generation/. Access at: 29.11.2010. 
Szumanowski A. 2000. Fundamentals of hybrid vehicle drives. Publishing and Printing House of the Institute for Sustainable Technologies - NRI, Warsaw-Radom.

Vas P. 1990. Vector control of AC machines. Clarendon Press, Oxford UK.

Zhu Z.Q., Howe D. 2007. Electrical machines and drives for electric, hybrid, and fuel cell vehicles. Proceedings of the IEEE, Vol. 95, No. 4.

\section{Biographical notes}

Jaroslaw Guzinski received the M.Sc. and Ph.D. degrees from the Electrical Engineering Department at the Technical University of Gdansk, Poland, in 1994 and 2000, respectively. Currently he is an Adjunct with the Faculty of Electrical and Control Engineering at Gdansk University of Technology, Poland. His current interests include sensorless control of electrical motors, digital signal processors and electric vehicles.

Haithem Abu-Rub (M’99-SM’07) received Ph.D. degree in 1995 from Electrical Engineering Department at the Technical University of Gdansk in Poland. Since 1997 he has been with Birzeit University in Palestine. Currently, he is the Chairman of Electrical Engineering Department and holds the position of associate professor. His main research interests include electric motor drives, power electronics, and electrical machines.

Received xx, 2010

Accepted November 2010

Final acceptance in revised form December 2010 